\title{
Young people and their understanding of loss and bereavement.
}

\author{
SCOTT, R., WALLACE, R., AUDSLEY, A. and CHARY, S.
}

2019

This is an Accepted Manuscript of an article published by Taylor \& Francis in Bereavement Care on 1/5/2019, available online: $\mathrm{http}: / / w w w . t a n d f o n l i n e . c o m / 10.1080 / 02682621.2019 .1588560$ 


\section{Young people and their understanding of loss and bereavement}

Dr Ros Scott, Honorary Research Fellow, University of Dundee, rosc.scott@btinternet.com

Professor Rebecca Wallace, Emeritus Professor, Robert Gordon University, Aberdeen, r.m.m.wallace@rgu.ac.uk

Annie Audsley, Project Research Assistant, annie.audsley26@gmail.com

Dr Srini Chary, Consulting Physician, Regional Palliative and Hospice Care, Calgary Zone \& Clinical Assistant Professor, Cummings School of Medicine University of Calgary, srini.chary@albertahealthservices.ca

Acknowledgement: We would like to acknowledge the funding and support for this study from Pallium Canada

Authors: Dr Ros Scott ${ }^{1}$, Honorary Research Fellow, Professor Rebecca Wallace, Emeritus Professor $^{2}$, Annie Audsley, Project Research Assistant ${ }^{2}$ and Dr Srini Chary, Consulting Physician, Clinical Assistant Professor ${ }^{3,4}$

${ }^{1}$ University of Dundee, ${ }^{2}$ Robert Gordon University, Aberdeen, ${ }^{3}$ Regional Palliative and Hospice Care, Calgary Zone. ${ }^{4,}$ Cummings School of Medicine University of Calgary.

\section{Bereavement Journal}




\begin{abstract}
A significant proportion of secondary school pupils in the UK have experienced the death of someone close. Bereavement in childhood can have a significant and long lasting impact. The aim of this study was to explore how pupils aged between 12 and 18 understand major loss, death and dying, whom they talk to and the support they access at these times, and their awareness of the range of support available to them. A total of 31 pupils, 108 parents and 37 staff from a large Scottish secondary school took part and data was collected using online questionnaires. A high proportion of pupils had experience of major loss or bereavement and showed significant awareness of their feelings and responses to these. It appears that young people primarily seek support from family and friends, but the role of peers is less well recognised by parents and teachers. The school was recognised as a source of support mainly by teachers.
\end{abstract}

Key words: pupils, peers, parents, teachers, major loss, bereavement

\title{
Introduction:
}

Interest is growing in the impact of loss and bereavement in schools. However, an early scoping exercise undertaken by the authors suggests that topics are seldom taught and conversations about death and dying seem to be left to the pupil, peers and family.

Often, external resources are available to pupils who are exposed to major illness of parents and siblings. Schools, when exposed as a group to major trauma, seem to have access to such resources in most communities. The age at which children begin to understand loss and bereavement varies by study. Piagetian theory (Piaget,1970) regarding appreciation of death holds that children do not have a sophisticated understanding of death until age nine or ten.

Research suggests that bereavement in childhood can have a significant impact and long-term consequences. Children respond to bereavement in different ways depending on factors including their age and understanding of death. A study by Abdelnoor and Hollins (2003) found that bereaved children experience high levels of anxiety and may underperform at school. Indeed, it is suggested that they may require periodic ongoing support throughout their time in education (Abdelnoor and Hollins, 2003). Children may also demonstrate regressive behaviour and teenagers may engage in in risk taking including truancy, substance abuse and petty crime (Holland 2008). There is evidence of support for bereaved children in schools but Holland (2008) suggests that it is geographically patchy.

Moreover, adverse events in childhood and ongoing stress, with impaired coping skills, can alter some of the hormonal production in the body leading to faulty processing of environmental threats and exaggerated stress 
reactions that can result in depression. Childhood negative experiences along with impaired coping may have lasting effects due to changes in the anatomy and function of parts of the brain leading to epigenetic effects. Certain circumstances in life can cause genes to be silenced or suppressed over time. In other words, they can be turned off (becoming dormant) or turned on (becoming active). What you eat, where you live, who you interact with, when you sleep, how you exercise, even aging - all of these can eventually cause chemical modifications around the genes that will turn those genes on or off over time (Marije aan het Rot et al, 2009; Stevens, Rucklidge and Kennedy, 2017). Further research is needed around the full range of psycho-social and physical impacts of bereavement in childhood and it must also be noted that research shows bereaved young people also can show resilience and effective coping (Feigelman et al, 2017).

Bereavement within the school population is common. In the UK alone it is estimated that $78 \%$ of $11-16$ year olds have experienced the death of a close relative or friend (Childhood Bereavement Network, no date). In Scotland, it estimated that approximately 25,000 children aged 5 to 16 years have been bereaved of a parent or sibling (Childhood Bereavement Network, 2016). Research has also shown that children are very curious about death and that even the most sheltered of children are exposed to death through movies, TV shows, books, news programmes and even video games (Gutierrez et al, 2014; Miller, Rosengren, \& Gutierrez, 2014). Hence, the investigators felt that a 'proof of concept study', exploring the area of school children exposed to loss or bereavement, could have major learning in relation to safe educational approaches to support better coping in bereaved young people.

This paper reports on the findings from the study undertaken in Scotland which explored young people's experiences of different types of loss, including the loss of someone close. However, the focus of this paper is mainly on findings related to bereavement.

\section{Research questions}

Five research questions were addressed:

- What are young people's understanding of change, loss and death at ages 10-18?

- To whom, and how, do young people communicate their understanding of change, loss and death?

- What coping skills do young people demonstrate in dealing with change, loss and death?

- What support are they aware of and do they choose to access this?

- How do parents and teachers engage with young people about losses including death dying and bereavement? 


\section{Ethical considerations}

Ethical approval for the 'proof of concept study' was obtained initially from the University of Calgary, Canada and the Calgary Board of Education had to approve such study in a Calgary school. In Scotland ethical approval was obtained from Robert Gordon University, Aberdeen.

It was a collaborative study between Calgary, Alberta, Canada and Scotland as the research team in Canada had been exploring loss, trauma, including death and dying, in school children and different fundamental theories around the effects of bereavement. The investigators had been corresponding and collaborating for a joint 'proof of concept study' and to research further internationally, if it was proven feasible and useful.

All young people were encouraged in Calgary and Scottish schools to discuss participation with their parents or guardian. Young people under the age of 16 years required the signed consent of a parent or guardian for participation. Quotes from young people are included anonymously, in the text when appropriate.

\section{Methodology}

This was primarily a qualitative study with a small number of quantitative questions to give context. Pupils, parents and teachers were contacted by the school and invited to take part. Three online questionnaires were designed tailored for pupils, parents and staff respectively. These were piloted and revised before being disseminated using Survey Monkey. Questionnaires included multiple choice and open text questions.

The proposed sample sought 20 participants for each group. The response, however, exceeded this and given the high level of interest in the study, it was decided not to restrict the sample size in order to maximise the data collected. The final sample comprised 31 pupils (14 male and 17 female), 108 parents and 37 staff. Pupils were aged between 12 and 18 years of age. Numerical data were analysed using Survey Monkey. A thematic analysis of free text data was also undertaken. It should be noted, however, that the parents included in the study are not necessarily those of the pupils who took part as this was not a requirement of the study.

\section{Findings from Scottish Study:}

\section{Young people's feelings in response to loss and death}

Young people were asked to select a range of words that described their feelings in three different contexts: 1) losing an item which was important to them, 2) encountering the death of a character in a fictional situation (for example television programmes or computer game) and 3) losing someone close to them, either through death or the person moving away. Multiple words could be selected from the list given with the option to add terms of their own choice. 
In response to losing an item of importance the words most frequently selected most frequently included 'panic', 'frustrated', 'annoyed' and 'worried' indicating a range of different emotions.

'Because I was scared of what I was going to do or how I would tell my parents as they would be disappointed in me'

'I would make me feel angry and sad because it might be special to you and that if you loose it you might never find it again.'

Some young people indicated that they were affected by death in a fictional setting selecting words such as 'sad', 'annoyed', 'angry' and 'disbelief' to describe their feelings. Others were less so, choosing words such as 'unconcerned' and 'calm'. Young people were overwhelmingly clear that they felt differently about loss in a fictional setting to losing an item of importance.

'People don't really die'

'The characters are not important me'

The majority of young people (90\%) had experienced the loss of someone close to them, either through separation, moving away or through death. Almost all pupils selected 'sad' (89\%) followed by "Ionely" (46\%), 'disbelief' and 'shocked' (43\%), 'empty' (39\%), 'confused' and 'annoyed' (32\%). Additional words chosen by young people included 'devastated' and 'depressed'.

It was clear from the responses that young people experienced a range of different feelings in each context. However, it is interesting to note that the number of words selected was distinctly different for each. Between six and ten words per respondent were indicated in response to losing someone close, considerably more than in response to losing an important possession or encountering death in a fictional situation.

In further exploring different kinds of loss, young people were then asked to imagine how they would feel in the event of a friend leaving the school or alternatively a fellow pupil who had bullied them. Almost all young people expressed sadness at a friend leaving school and relief or happiness at a bully leaving. However, a small percentage in each question expressed a more complex response: an element of happiness for their friend moving on to new experiences, or some negative emotions towards 'the bully', for example, in 'getting away with it'.

'Would feel sad but I would be happy for her to be in a new house and new school and new friends'

'It would make me feel happy, as I was free from the difficult situation'

'Bad because they would get away with it' 
Young people were also asked about their feelings about the death of an older person. More that half of respondents (55\%) selected 'it's still very sad' with fewer highlighting 'it's natural', perhaps reflecting acceptance of the inevitability of death. A small number of young people $(6 \%)$ suggested 'age makes no difference'.

\section{Where young people find support}

Young people were asked if they were aware of the support available to them if someone close to them died. Just over half gave an affirmative answer to this question. Young people identified a number of different people to whom they turned in such situations. Most young people turned to parents $(87 \%)$ and friends $(65 \%)$ whilst a smaller number turned to siblings (52\%) and/or grandparents (48\%). A small percentage of young people sought help from boyfriends or girlfriends $(20 \%)$, $19 \%$ from teachers and other relatives (16\%).

'Family are the best support I ever had when I lost $X$ who was stillborn. Online aids could also help a young person who is not close/able to speak to their family'.

Beyond the family, social and school networks, a minority of young people (3\%) turned to faith leaders, helplines and counsellors. One pupil responded ' $I$ keep it to myself' whilst another sought comfort in 'my dog'. In terms of accessing support, findings suggest that only around one third of respondents had done so. As outlined previously, of who had sought support, family and friends were the main sources of support that young people accessed.

"I spoke to my family and friends when I lost $x$. We found it was easier to speak about our grief than hold it in and not talk about it".

'My best friend was always there for me when my granddad died and it made me feel good having my best friend by my side.'

Relatively few young people acknowledged awareness of any kind of formal support either in school or from external organisations. Even fewer had accessed such support. Within the school community only the support of a guidance teacher had been sought. Formal support identified included a local youth organisation, Child Line 'counselling' and 'online advice'.

'After a family member then a teacher died I managed to get help through both' (both parents and school guidance team).

'When my sister died and after my great gran died. And when my other sister was seriously ill as a child'. (Pupil had turned to parents and accessed counselling)

In concluding the survey, a number of young people chose to add unprompted comments such as:

'Losing a loved one is difficult and it doesn't get any easier as time goes on. You still think about the death and the loss everyday but if you don't pick yourself up and try 
and get back to normal then it will consume your everyday life and that's not a healthy situation to be in'.

'It is always very difficult when someone dies even though it is part of life. Even though it is normal I like to have people there to listen to me and comfort me when I am sad'.

'My brother died when I was younger and although I was only young it has had a huge impact on my life, sometimes I feel guilty and angry that he had to die, but I have had great support from my close friends and family'.

At all stages of the questionnaire, young people, irrespective of age, displayed considerable insight into their own experiences of loss and bereavement and as to how they coped. Evidently distinguishing between the loss of an item, death in fictional settings and real life, young people were able to express clear reasons for their feelings. This respondent group was also thoughtful about the implications of death later in life. Concerns about how young people might respond to the survey were allayed by the full and thoughtful answers given to each question. Indeed one young person added 'I really enjoyed this survey'. It must be considered, however, that as young people self-selected to take part in this study, that it may be that those most comfortable with the subject area were more likely to participate.

\section{What young people find most helpful}

Having considered the people to whom young people turned, the study also explored what those people did that young people found helpful. The majority identified people who listened, understood and comforted them as being of most value. A small number found being encouraged to talk and giving them space to be helpful. Others also found that being able to "watch a movie and talk" and "let me express my feelings".

In addition, young people were asked what else they found helpful. Areas selected most frequently included spending time with friends and music, followed by sport / being active and books. A minority selected 'information' or 'online advice'. Additional activities suggested by young people included 'playing games with family such as Monopoly or Cluedo', 'painting'. One young person proposed 'Keeping my mind off it and not spending too much time thinking about it'.

This cohort of young people seem to find the most support within existing family and social networks and interests. Interestingly, only around a quarter selected social media, suggesting that, at least for these respondents, face-to-face contact with family and friends is preferred.

\section{Parent and teacher conversations with young people about loss and death}

The study then explored the views of parents and teachers in talking with young people about loss and death. The majority of both parents and teachers had held these conversations with young people, however, $3 \%$ of parents and $22 \%$ of teachers indicated that they had not engaged in such discussions. Two key points 
emerge: firstly, such conversations usually only take place when a young person has been affected by a death, and secondly, the reluctance expressed by both groups was as a result of their fear of causing distress. Of the respondents who had not engaged in these discussions the majority of parents and teachers indicated that 'there had not been an opportunity' with approximately one third of parents and a quarter of teachers responding that 'I was afraid of causing upset'. Only teachers responded that they were 'concerned how the young person would react' or 'I was not sure what to say'.

The number of teachers who had not had such conversations, only because of fear of upset or not knowing what to say, was small. However, it was still $5 \%$ of all the teachers who took part in the study. If this was to be the norm across schools, it would suggest that a substantial body of teachers feel ill equipped to discuss loss and death with pupils.

As to whom should have these conversations with young people, the adults in this study identified families as being the best people to engage in such discussions. A large majority of teachers (85\%) and a smaller percentage of parents $(65 \%)$ also saw teachers as being appropriate to have these conversations.

Evidence from all respondent groups suggests that young people, at least in this particular school, discuss their feelings about loss and death primarily with their parents and friends. These conversations most often happen in response to a young person having experienced bereavement.

\section{Parents' understanding of support available to young people}

Parents were asked where they would direct a young person in need of support. Some held quite strong views that this should remain within the family:

'We would deal with this at home as a family'.

'We as parents would be first port of call for that'.

'They've got all the support they need at home'.

'I personally would not appreciate someone else speaking to my child on a one to one basis. If in a group discussion with other children and with someone who knows what they are doing, then that is fine and only for educational purposes."

Other parents were of the opinion that sources of support external to the family might be beneficial. One suggested that a young person should speak to 'anyone they're comfortable with' and another said 'My daughter has counselling at school, it has really helped as she needed to talk without the family'.

As can be seen in Figure 1, only 32\% of parents would suggest their children turn to their friends or peer group. It is interesting to note that whilst young people, in common with their parents, identified strongly with family as a key source of support, young people also found their friends to be important to them at such times. 


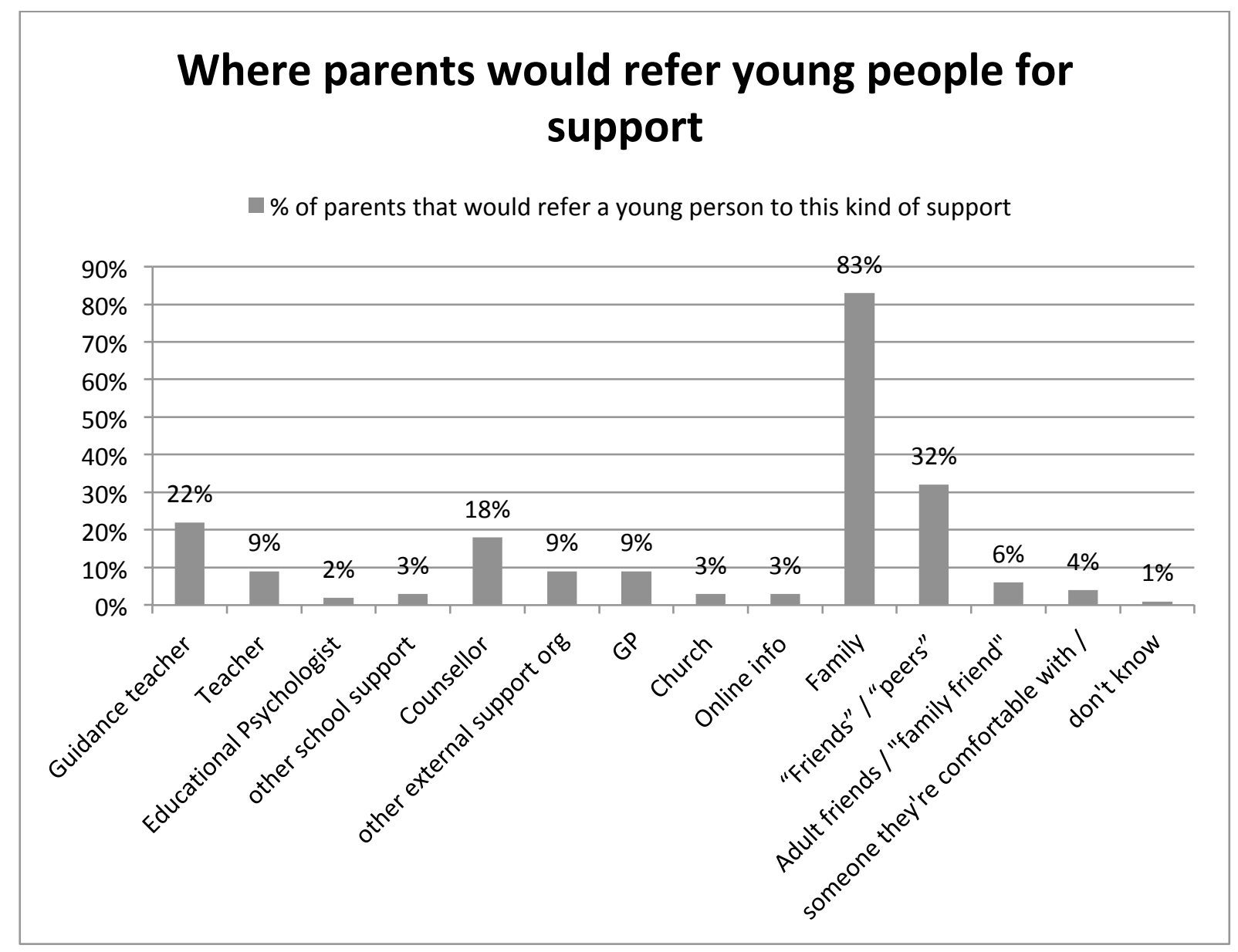

Figure 1

As can be seen from Figure 1, school support, including guidance teachers, teachers and other sources were acknowledged as a referral option. In addition, external agencies were also highlighted and those identified included: Barnardo's Roller Coaster Project, Cruse Scotland, Maggie's Centre, Women's Aid Children's Team, MacMillan Cancer Support, a local youth organisation, and a counselling agency. Parents were subsequently asked whether their child had accessed any kind of bereavement support. Responses showed that only 3\% had accessed support at school and 6\% from external agencies. The specific types of support accessed included: Maggie's Centre, guidance teacher, private counsellor, Barnardo's Roller Coaster Project, Women's Aid Children's Team, Art Therapy from the local Council on Alcohol.

It is interesting to consider that even though young people spend so much time at school, pupils and parents in this study did not identify this as a key source of support. Indeed, of those young people who had accessed support, more had done so through external agencies rather than through the school. The reasons for this are not clear, but it may be because they sought specialist bereavement support, perhaps were unsure whether such support was available to them within school or possibly did not want to share their story or feelings within the school context. 


\section{Teachers' understanding of support available to young people}

The responses collected from teachers differ markedly from those of parents and young people. Perhaps unsurprisingly, they emphasised school support, with the primary support being identified as the pupil's guidance teacher $(94 \%)$. As can be seen in Figure 2, only $12 \%$ of teachers suggested that they would refer a child to their parents or family and only $9 \%$ to a friend.

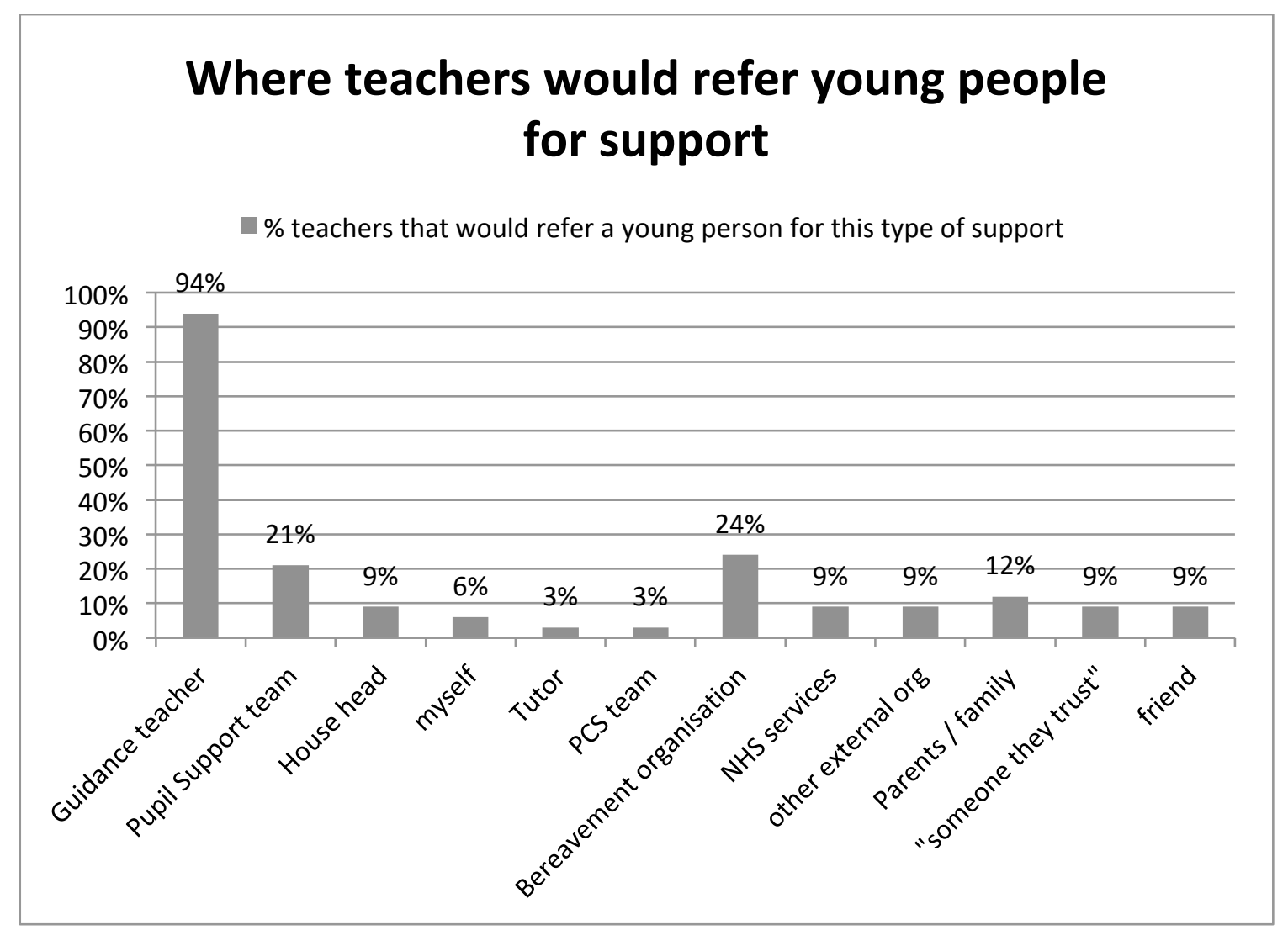

Figure 2

External organisations also identified by teachers were very similar to those identified by parents or accessed by young people as outlined previously. However, teachers were the only group to identify NHS services. 


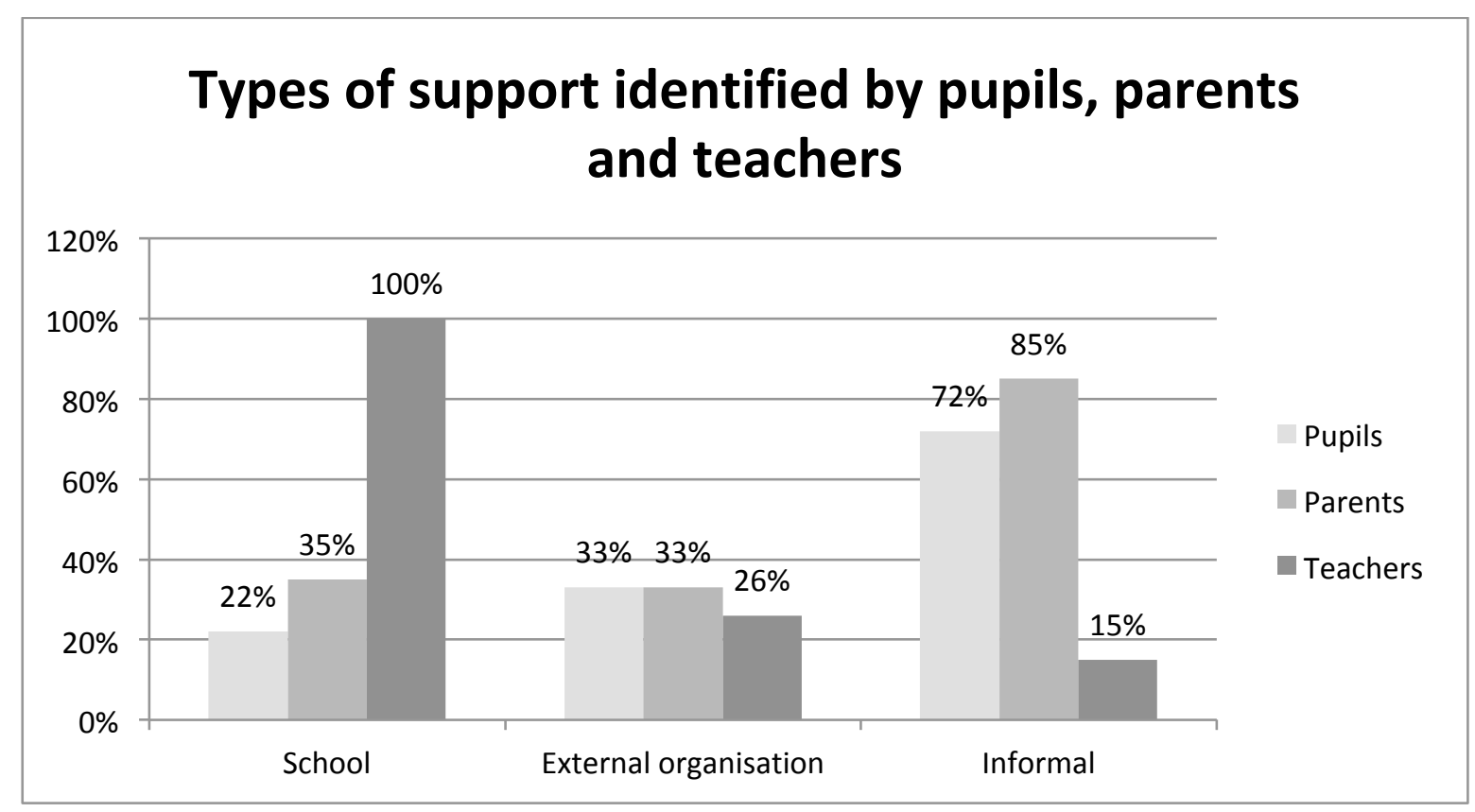

Figure 3

Figure 3 gives a comparison of the support identified by the three participant groups. Teachers identified school support more frequently than either of the other two groups. The proportion of teachers, parents and pupils who highlighted external organisations is broadly similar and relatively low. This may be more to do with the context in which the parent or teacher engages with the young person than their opinion as to the appropriateness of the particular support. Both parents and young people identify more strongly with the informal support of family and friends than with support from teachers.

\section{Strengths and Limitations}

A key strength of this study was the high level of interest and quality of responses. Notwithstanding this, researchers found it more difficult to recruit young people to the study than either parents or teachers. The reasons for this are not immediately evident. Funding and time constraints precluded any follow up to the questionnaires to explore the findings in more depth. The collected data came from one school with a catchment area and so these findings may not necessarily apply in other school contexts.

\section{Conclusion}

A significant number of young people involved in this study had experienced major loss and bereavement. They showed considerable insight into of different types of loss and their emotional responses to these. Coping skills in this group also appeared to be strong. Primarily young people find support from families, friends also finding their interests and hobbies helpful. Parents also strongly believe that family should be the main source of support at these times. It is disappointing to note that neither parents nor young people identified strongly with school as a place 
where young people could turn for support. However, the findings also suggest that teachers have a support role to play. Some of the findings may be partially biased as parents received the questionnaire. If there was collaboration between pupil and parents, expression may not be independent.

It is interesting to note that the internet, social media and written information seems to be of less importance to young people in this study when seeking support. Peers are clearly important to this group at difficult times, however, this is less well recognised by parents and teachers. A participatory approach to developing bereavement support frameworks in schools, reflecting the views and experiences of young people could be beneficial. Perhaps the time is right to recognise the valuable insights that young people have to offer.

\section{Recommendation}

It is recognised that the findings of this study can only be seen from the perspective of this particular school and therefore it is recommended that further research be undertaken in schools with diverse socioeconomic, ethnic and geographical catchments.

aan het Rot, M., Mathew, S. J., \& Charney, D. S. (Feb 2009). Neurobiological mechanisms in major depressive disorder. CMAJ, 180(3) 305-313.

Abdelnoor, A., \& Hollins, S. (2004). The effect of childhood bereavement on secondary school performance. Educational Psychology in Practice, 20(1), 43-54.

Childhood Bereavement Network (no date). National Statistics. Accessed on 15 June 2018 from http://www.childhoodbereavementnetwork.org.uk/research/keystatistics.aspx

Childhood Bereavement Network (2016). Key estimated statistics on childhood bereavement. Accessed on 15 June 2018 from

http://www.childhoodbereavementnetwork.org.uk/media/53767/Key-statistics-onChildhood-Bereavement-Nov-2016.pdf

Gutierrez, I. T., Miller, P. J., Rosengren, K. S., \& Schein, S. S. (2014). Children's understanding of death: Toward a contextualized and integrated account: III. affective dimensions of death: Children's books, questions, and understandings. Monographs of the Society for Research in Child Development, 79(1), 43-61.

Holland, J. (2008). How schools can support children who experience loss and death. British Journal of Guidance and Counselling, 36(4), 411-424.

Miller, P. J., Rosengren, K. S., \& Gutierrez, I. T. (2014). Children's understanding of death: Toward a contextualized and integrated account: I. introduction. Monographs of the Society for Research in Child Development, 79(1), 1-18. 
Piaget. J. (1970), Piaget's theory. In P.H. Mussen (Ed.), Carmichael's manual of child psychology (Vol. 1, 3rd ed.), New York: Wiley, pp. 703-732.

Stevens A. J., Rucklidge J.J. \& Kennedy M. A. (2017). Epigenetics, nutrition and mental health. Is there a relationship? Nutr Neurosci, 1-12. Doi:

10.1080/1028415X2017.1331424. 